\title{
Prophylactic Antibiotics Reduce Pancreatic Necrosis in Acute Necrotizing Pancreatitis: A Meta-Analysis of Randomized Trials
}

\author{
Linhua Yao Xiayue Huang Yuqin Li Ruihua Shi Guoxin Zhang \\ Department of Gastroenterology, The First Affiliated Hospital of Nanjing Medical University, Nanjing, China
}

\section{Key Words}

Prophylactic antibiotic · Randomized controlled trial •

Acute necrotizing pancreatitis

\begin{abstract}
Background and Aim: The use of prophylactic antibiotics to prevent infection and reduce mortality in patients with acute necrotizing pancreatitis (ANP) remains controversial. The aim of this study is to perform a systematic review of the data from randomized controlled trials to compare prophylactic antibiotic treatment of patients with ANP versus placebo. Methods: A computerized literature search was conducted using Medline, PubMed, EMBase and Cochrane Central Register of Controlled Trials (CENTRAL) for relevant articles published in English from January 1990 to March 2010. MeSH terms and keywords used to identify articles included 'antibiotic', 'pancreatitis', and 'randomized'. Outcome measures were infected pancreatic necrosis (IPN), mortality, nonpancreatic infection (NPN) and need for surgical intervention. Results: Nine trials involving 564 patients were included. Analysis suggested that IPN was significantly reduced by treatment with antibiotics (RR $0.73,95 \% \mathrm{Cl} 0.54-$ $0.98, p=0.04)$. Mortality $(p=0.1)$, NPN $(p=0.07)$, and need for surgical intervention ( $p=0.17$ ) were not significantly reduced by antibiotic treatment. Subsequent subgroup analy-
\end{abstract}

sis confirmed that antibiotics were statistically superior to controls in reducing of infected necrosis $(p=0.003)$ and also mortality $(p=0.02)$ in single-blinded randomized controlled trials. Conclusion: Prophylactic antibiotic treatment reduced occurrence of IPN, but did not affect mortality, NPN, or surgical intervention in patients with ANP.

Copyright $\odot 2010$ S. Karger AG, Basel

\section{Introduction}

Acute necrotizing pancreatitis (ANP), with a high mortality rate of $10-30 \%[1,2]$, is a serious clinical emergency. Due to improvements in intensive care units and radiological techniques, more patients now survive the onset phase of 1-2 weeks, so more attention has been focused on the later phase of the disease. Pancreatic and peripancreatic infection are the major factors leading to morbidity and mortality in the latter phase of ANP with reported rates as high as $40-70 \%[3,4]$.

Although the mechanisms of bacterial infection are unknown, experimental and clinical research suggests that gut pathogens in residence prior to infection translocate from the gastrointestinal tract to the pancreas. Beginning in 1975, randomized controlled trials (RCTs) have been conducted to determine the effect of prophylactic

\section{KARGER}

Fax +4161306 1234

E-Mail karger@karger.ch

www.karger.com (c) 2010 S. Karger AG, Basel

0253-4886/10/0276-0442\$26.00/0

Accessible online at:

www.karger.com/dsu
Guoxin Zhang

Department of Gastroenterology

The First Affiliated Hospital of Nanjing Medical University

300 Guangzhou Road, Nanjing 210029 (China)

Tel. +86 258371 8836, E-Mail guoxinz@ njmu.edu.cn 
antibiotics in ANP treatment. The initial trials were criticized for enrolling patients without severe disease and for administering inadequate antibiotics [5-7]. Three types of antibiotics, carbapenems, fluoroquinolones, and cephalosporins, have been found to penetrate into the pancreas $[8,9]$. During the past decades, a number of studies have been done in order to determine whether it is necessary to administer antibiotics for ANP with conflicting results [10-18]. Meta-analyses have also been inconclusive [19-24]. Due to lack of a definitive study on use of prophylactic antibiotic treatment, various guidelines also suggest different recommendations [25-29]. In order to clarify the role of prophylactic antibiotic treatment of patients with ANP, we performed a meta-analysis of all available literature to evaluate the efficacy of antibiotic prophylaxis.

\section{Materials and Methods}

\section{Literature Search and Inclusion Criteria}

A computerized literature search was conducted using Medline, PubMed, EMBase and Cochrane Central Register of Controlled Trials (CENTRAL) for relevant articles published in English from January 1990 to March 2010. MeSH terms and keywords used to identify articles included 'antibiotic', 'pancreatitis', and 'randomized'. Boolean operators ('NOT', 'AND', 'OR') were used in succession to narrow and widen the search. Symposia proceedings, poster presentations, and abstracts from major gastrointestinal meetings were also searched. For inclusion in the metaanalysis, articles had to meet the following criteria: (a) study design: RCT; (b) study population: AMP patients with CT-proven necrosis; (c) intervention: prophylactic administration of $\beta$-lactam, quinolone, or cephalosporin antibiotic; (d) comparison intervention: placebo or no treatment; (e) outcome measures: infected pancreatic necrosis (IPN), mortality, nonpancreatic infection $(\mathrm{NPN})$, surgical intervention. The search was limited to human studies and there were no language restrictions.

\section{Data Extraction}

Data from each paper fulfilling inclusion criteria were reviewed and data were separately extracted by two independent investigators (L.Y. and Y.L.); discrepancies were resolved through discussion. Major items were collected into a standardized data extraction form that included treatment regimen, the exact methods of prophylactic antibiotic use, the etiology of this disease, and the method of feeding. The major outcomes included IPN, mortality, NPN, and need for surgical intervention.

\section{Quality Assessment}

The scale developed by Jadad et al. [30], a validated instrument for assessing the quality of randomized studies, was used to independently rate the quality of the selected randomized trials by two authors (L.Y. and Y.L.). Scores ranged from 1 to 5: a score of $<3$ indicated a lower study quality, whereas studies achieving a rating of $\geq 3$ were considered of higher quality and were used as part of the sensitivity analysis. Any disagreement was resolved by discussion between the two reviewers.

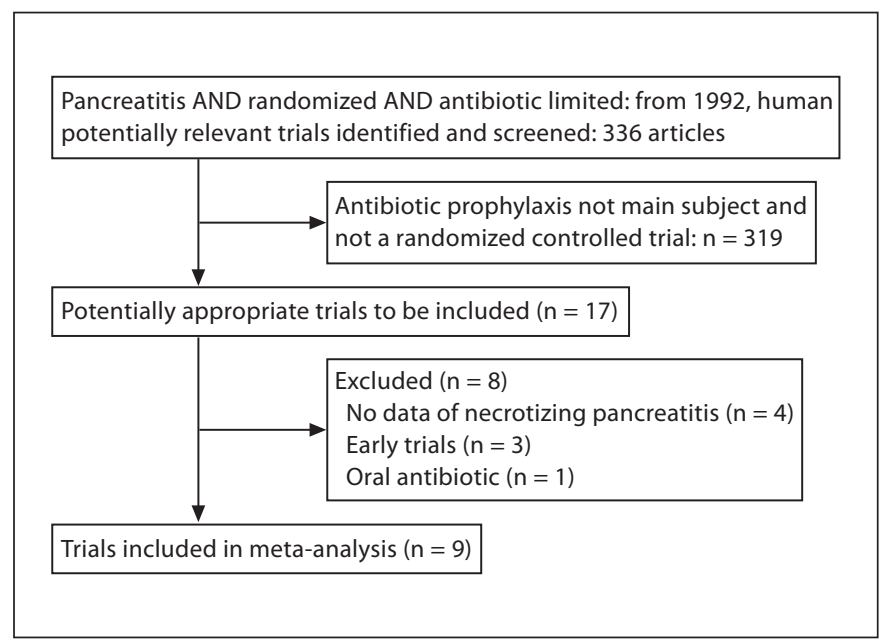

Fig. 1. Flowchart illustrating the details of the search and study selection process.

\section{Statistical Analysis}

The analysis was conducted in Review Manager 4.2.8. Crude analysis and subgroup analysis were performed for included outcomes. The relative risk (RR), the odds ratio (OR) and the $95 \%$ confidence interval (CI) for major outcomes were estimated for each study in a random-effects model or in a fixed-effects model. For each group, we estimated the between-study heterogeneity. However, since tests of heterogeneity had a relative low power, the threshold for significance was set at a high level and a $\mathrm{p}$ value of $<0.100$ indicates significant heterogeneity. If there was a significant heterogeneity, we selected a random-effects model to pool the data. If not, we selected a fixed-effects model to pool the data. However, because this test is underpowered when there are a limited number of studies, we further explored heterogeneity derived from another statistical method, the $\mathrm{I}^{2}$ metric, which is independent of the number of combined studies and describes the proportion of variability across studies that is due to genuine heterogeneity and measures the degree of inconsistency across studies. If $\mathrm{I}^{2}$ equals $0 \%$, there is no heterogeneity. If $\mathrm{I}^{2}>50 \%$, heterogeneity is indicated. The larger the value, the greater the heterogeneity.

\section{Results}

\section{Eligible RCTs}

The literature search yielded 336 publications. The details of the literature search and selection of studies are shown in figure 1.17 potentially eligible RCTs on AMP were identified and 8 of these studies were excluded. In the 9 studies we included (table 1 ) were 2 new RCTs [17, 18] that had not previously been included in meta-analyses of this subject. 


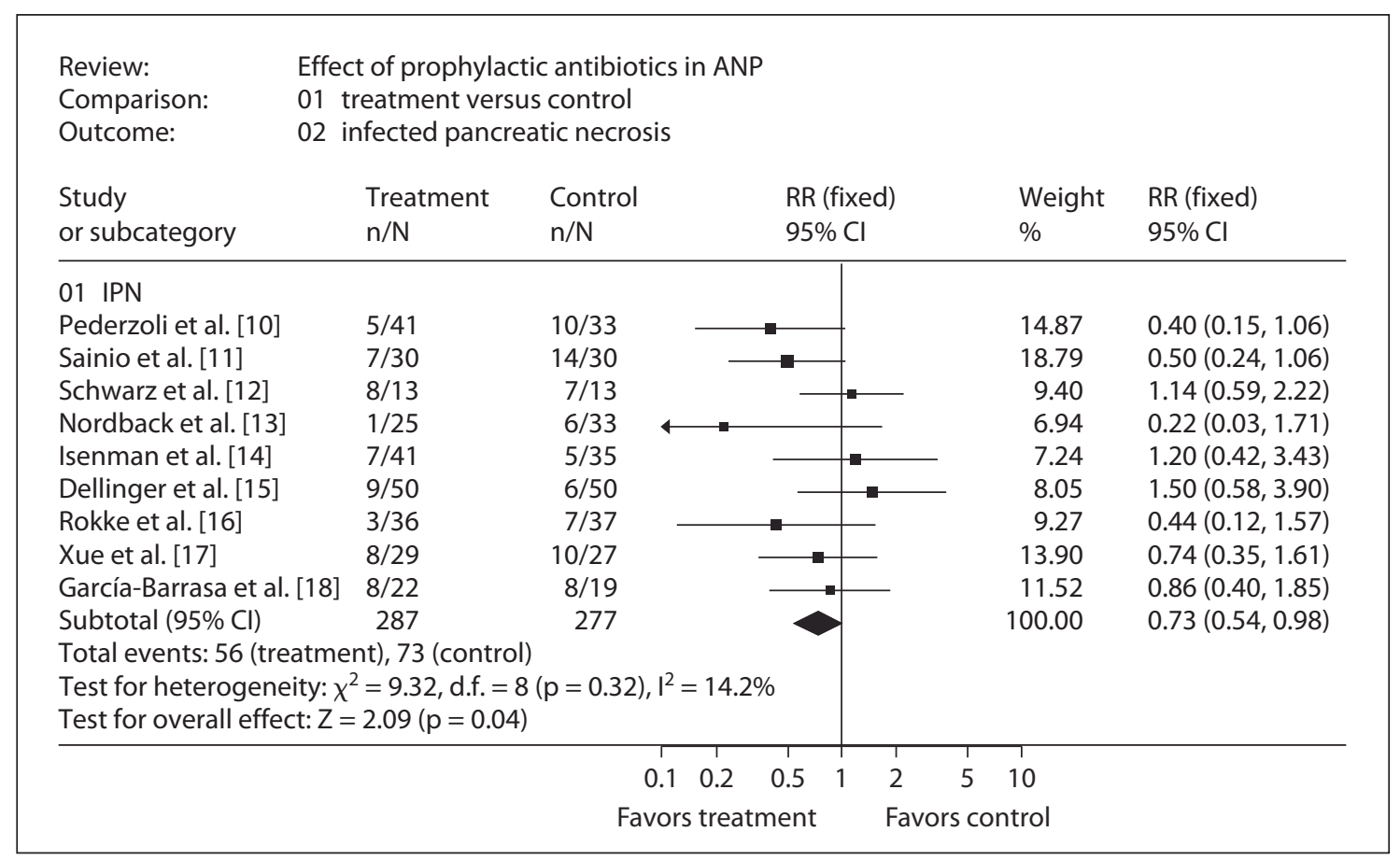

Fig. 2. Antibiotic prophylactic effect on IPN.

Table 1. Characteristics of RCTs included in the meta-analysis

\begin{tabular}{|c|c|c|c|c|c|c|c|}
\hline First author & Year & Setting & Blinded & Antibiotic & Patients, $\mathrm{n}$ & $\begin{array}{l}\text { Quality } \\
\text { ranking }\end{array}$ & $\begin{array}{l}\text { Method } \\
\text { of feeding }\end{array}$ \\
\hline Pederzoli [10] & 1993 & Multi-center & Single & Imipenem, $0.5 \mathrm{~g}$, for 14 days & 74 & 1 & EN \\
\hline Sainio [11] & 1995 & Single-center & Single & Cefuroxime, $1.5 \mathrm{~g}$, every day & 60 & 3 & NR \\
\hline Schwarz [12] & 1997 & Single-center & Single & $\begin{array}{l}\text { Ofloxacin, } 200 \mathrm{mg} \text {, twice a day } \\
\text { Metronidazole, } 500 \mathrm{mg} \text {, twice a day }\end{array}$ & 26 & 2 & NR \\
\hline Nordback [13] & 2001 & Single-center & Single & Imipenem-cilastatin, $1 \mathrm{~g}, 3$ times a day & 39 & 3 & EN \\
\hline Isenmann [14] & 2004 & Multi-center & Double & $\begin{array}{l}\text { Ciprofloxacin, } 800 \mathrm{mg} \text {, every day } \\
\text { Metronidazole, } 1 \mathrm{~g} \text {, every day }\end{array}$ & 76 & 5 & NR \\
\hline Dellinger [15] & 2007 & Multi-center & Double & Meropenem, $1 \mathrm{~g}$ intravenously, every $8 \mathrm{~h}$ & 100 & 5 & EN \\
\hline Rokke [16] & 2007 & Multi-center & NR & Imipenem, $0.5 \mathrm{~g}$ intravenously, 3 times a day & 73 & 3 & EN \\
\hline Xue [17] & 2009 & Single-center & NR & Imipenem-cilastain, $3 \times 0.5 \mathrm{~g}$ within $72 \mathrm{~h}$ & 56 & 3 & NR \\
\hline García-Barrasa [18] & 2009 & Single-center & Double & Ciprofloxacin, $0.3 \mathrm{~g}$ every $12 \mathrm{~h}$ & 41 & 5 & NR \\
\hline
\end{tabular}

$\mathrm{EN}=$ Enteral nutrition; NR $=$ not reported.

\section{Infected Pancreatic Necrosis}

There were 564 patients included in the nine trials comparing antibiotics with placebo or no treatment on prevention of IPN (fig. 2). The reduction in IPN was significant when patients were treated prophylactically with antibiotics (RR 0.73, 95\% CI 0.84-0.98, $\mathrm{p}=0.04$ ). When subgroup analyses were performed (table 2), data from both single-center (RR 0.69, 95\% CI 0.48-1.0, $\mathrm{p}=$
0.05) and single-blinded (RR 0.58, 95\% CI 0.40-0.83, $\mathrm{p}=0.003$ ) trials support the prophylactic effect of antibiotics in infection reduction. However, data from multi-center (RR 0.78, 95\% CI 0.47-1.29, p = 0.33) and double-blinded (RR 1.14, 95\% CI 0.68-1.93, p = 0.61) trials failed to support the prophylactic effect of antibiotics in infection reduction. The results with different antibiotic agents did not differ ( $\beta$-lactam: RR 0.64, 95\% 
Table 2. Subgroup analysis

\begin{tabular}{|c|c|c|c|c|c|c|c|c|}
\hline & \multirow[t]{2}{*}{ Outcome } & \multirow{2}{*}{$\begin{array}{l}\text { Number in } \\
\text { subgroup } \\
\text { (patients, n) }\end{array}$} & \multirow[t]{2}{*}{ RR (95\% CI) } & \multirow[t]{2}{*}{$\mathrm{Z}$} & \multirow[t]{2}{*}{$\mathrm{p}$ value } & \multicolumn{3}{|c|}{ Heterogeneity } \\
\hline & & & & & & $\chi^{2}$ & $\mathrm{p}$ & $\mathrm{I}^{2}, \%$ \\
\hline \multirow[t]{4}{*}{ Single-center } & IPN & $5(241)$ & $0.69(0.48,1.00)$ & 1.96 & 0.05 & 4.47 & 0.35 & 10.50 \\
\hline & Mortality & $5(241)$ & $0.52(0.25,1.06)$ & 1.81 & 0.07 & 4.35 & 0.36 & 8.00 \\
\hline & NPN & $4(181)$ & $1.02(0.69,1.50)$ & 0.09 & 0.93 & 4.7 & 0.2 & 36.10 \\
\hline & Surgery & $4(215)$ & $0.67(0.42,1.08)$ & 1.63 & 0.1 & 1.5 & 0.68 & 0 \\
\hline \multirow[t]{4}{*}{ Multi-center } & IPN & $4(323)$ & $0.78(0.47,1.29)$ & 0.97 & 0.33 & 4.99 & 0.17 & 39.80 \\
\hline & Mortality & $4(323)$ & $0.85(0.48,1.51)$ & 0.55 & 0.58 & 0.81 & 0.85 & 0 \\
\hline & NPN & $4(323$ & $0.53(0.38,0.75)$ & 3.64 & 0.0003 & 6.06 & 0.11 & 50.50 \\
\hline & Surgery & $4(323)$ & $0.92(0.62,1.38)$ & 0.4 & 0.69 & 1.86 & 0.6 & 0 \\
\hline \multirow[t]{4}{*}{ Single-blinded } & IPN & $6(347)$ & $0.58(0.40,0.83)$ & 2.94 & 0.003 & 6.24 & 0.28 & 19.80 \\
\hline & Mortality & $6(347)$ & $0.47(0.25,0.90)$ & 2.29 & 0.02 & 2.55 & 0.77 & 0 \\
\hline & NPN & $5(287)$ & $0.64(0.44,0.91)$ & 2.46 & 0.01 & 16.11 & 0.003 & 75.20 \\
\hline & Surgery & $5(321)$ & $0.74(0.50,1.10)$ & 1.5 & 0.13 & 1.99 & 0.74 & 0 \\
\hline \multirow[t]{4}{*}{ Double-blinded } & IPN & $3(217)$ & $1.14(0.68,1.93)$ & 0.5 & 0.61 & 0.84 & 0.66 & 0 \\
\hline & Mortality & $3(217)$ & $1.07(0.56,2.01)$ & 0.19 & 0.85 & 0.88 & 0.65 & 0 \\
\hline & NPN & $3(217)$ & $0.72(0.50,1.03)$ & 1.82 & 0.07 & 0.4 & 0.82 & 0 \\
\hline & Surgery & $3(217)$ & $0.92(0.56,1.51)$ & 0.32 & 0.75 & 1.83 & 0.4 & 0 \\
\hline \multirow[t]{4}{*}{$\beta$-Lactam } & IPN & $5(361)$ & $0.64(0.41,1.01)$ & 1.94 & 0.05 & 5.45 & 0.24 & 26.50 \\
\hline & Mortality & $5(361)$ & $0.81(0.47,1.38)$ & 0.78 & 0.44 & 1.09 & 0.9 & 0 \\
\hline & NPN & $5(361)$ & $0.66(0.49,0.89)$ & 2.76 & 0.006 & 15.07 & 0.005 & 73.50 \\
\hline & Surgery & $5(361)$ & $0.97(0.66,1.43)$ & 0.14 & 0.89 & 1.31 & 0.86 & 0 \\
\hline \multirow{4}{*}{$\begin{array}{l}\text { Quinolone/ } \\
\text { imidazole }\end{array}$} & IPN & $2(117)$ & $0.99(0.53,1.85)$ & 0.33 & 0.98 & 0.25 & 0.62 & 0 \\
\hline & Mortality & $2(117)$ & $1.00(0.36,2.80)$ & 0 & 1 & 0.83 & 0.36 & 0 \\
\hline & NPN & $2(117)$ & $0.77(0.46,1.30)$ & 0.97 & 0.33 & 0.25 & 0.62 & 0 \\
\hline & Surgery & $2(117)$ & $0.67(0.34,1.35)$ & 1.12 & 0.26 & 0.15 & 0.7 & 0 \\
\hline \multirow[t]{4}{*}{ Cephalosporins } & IPN & $2(86)$ & $0.71(0.43,1.18)$ & 1.31 & 0.19 & 2.8 & 0.09 & 64.30 \\
\hline & Mortality & $2(86)$ & $0.16(0.03,0.84)$ & 2.17 & 0.03 & 0.03 & 0.85 & 0 \\
\hline & NPN & $1(26)$ & $0.20(0.01,3.80)$ & 1.07 & 0.28 & & & \\
\hline & Surgery & $1(60)$ & $0.50(0.24,1.06)$ & 1.8 & 0.07 & & & \\
\hline
\end{tabular}

IPN = Infected pancreatic necrosis; NPN = nonpancreatic infection; RR = relative risk; $\mathrm{CI}=$ confidence interval.

CI 0.41-1.01, p = 0.05; quinolone-based agents: RR 0.99, 95\% CI 0.53-1.85, $\mathrm{p}=0.98$; cephalosporins: RR 0.77, 95\% CI $0.33-1.78, \mathrm{p}=0.54)$.

\section{Mortality}

Antibiotics were not associated with significantly reduced mortality (RR $0.69,95 \%$ CI $0.44-1.08, \mathrm{p}=0.1$ ) as summarized in figure 3 . When subgroup analyses were performed (table 2), only in trials with cephalosporins (single-center: RR 0.16, 95\% CI 0.03-0.84, $\mathrm{p}=0.03$, and single-blinded: RR $0.47,95 \%$ CI $0.25-0.90, \mathrm{p}=0.02$ ) was the mortality rate significantly decreased. The other two types of antibiotic agents did not have a significant effect on mortality ( $\beta$-lactam: RR $0.78,95 \%$ CI $0.44-1.09, \mathrm{p}=$ 0.44 ; quinolone-based agents: RR $1.00,95 \%$ CI 0.36-2.80, $\mathrm{p}=1.00$ ). In multi-center trials (RR $0.85,95 \%$ CI 0.48 $1.51, \mathrm{p}=0.58)$ and double-blinded trials (RR $1.07,95 \% \mathrm{CI}$
$0.56-2.01, \mathrm{p}=0.85$ ), the death rate was not a significantly affected by prophylactic use of antibiotics.

\section{Nonpancreatic Infection}

Eight studies reported patients who had NPN in both treatment and control groups ( $\mathrm{n}=504$; antibiotics: 65 of 257; placebo: 90 of 247). The effect of antibiotic treatment on NPN is summarized in figure 4. Antibiotic treatment was not associated with significant reductions in NPN (RR 0.67, 95\% CI 0.43-1.04, $\mathrm{p}=0.07$ ). When subgroup analyses were performed (table 2), treatment with $\beta$-lactam antibiotics did significantly reduce infections in multi-center trials (WHAT: RR 0.53, 95\% CI 0.38-0.75, $\mathrm{p}=0.0003$; WHAT: RR $0.66,95 \%$ CI $0.49-0.89, \mathrm{p}=0.006$ ), single-center RCTs (RR 1.02, 95\% CI 0.69-1.50, $\mathrm{p}=0.93$ ), single-blinded trials (RR 0.44, 95\% CI 0.15-1.27, $\mathrm{p}=0.13$ ) and double-blinded trials (RR 0.72, 95\% CI 0.50-1.03, p = 


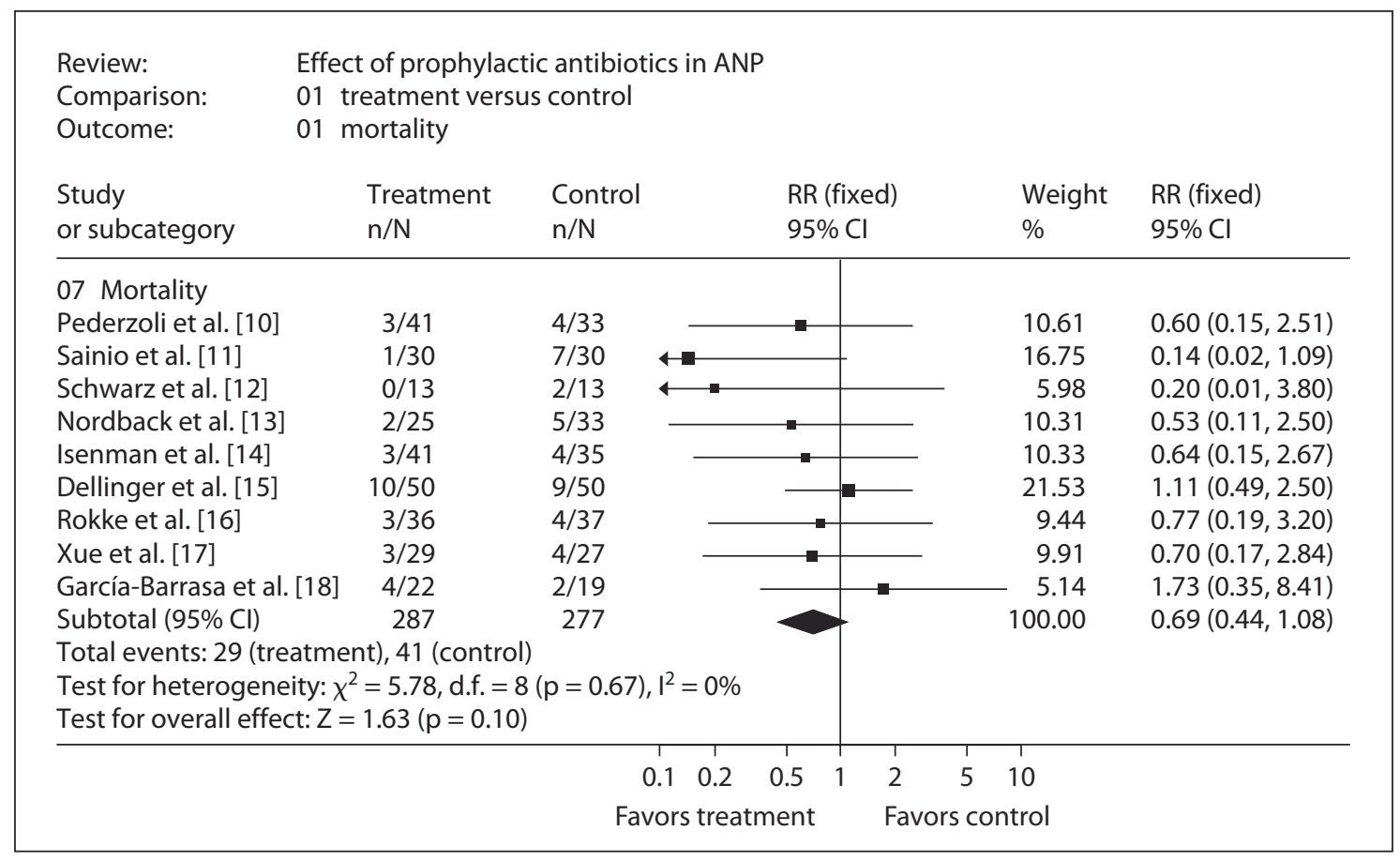

Fig. 3. Antibiotic prophylactic effect on mortality.

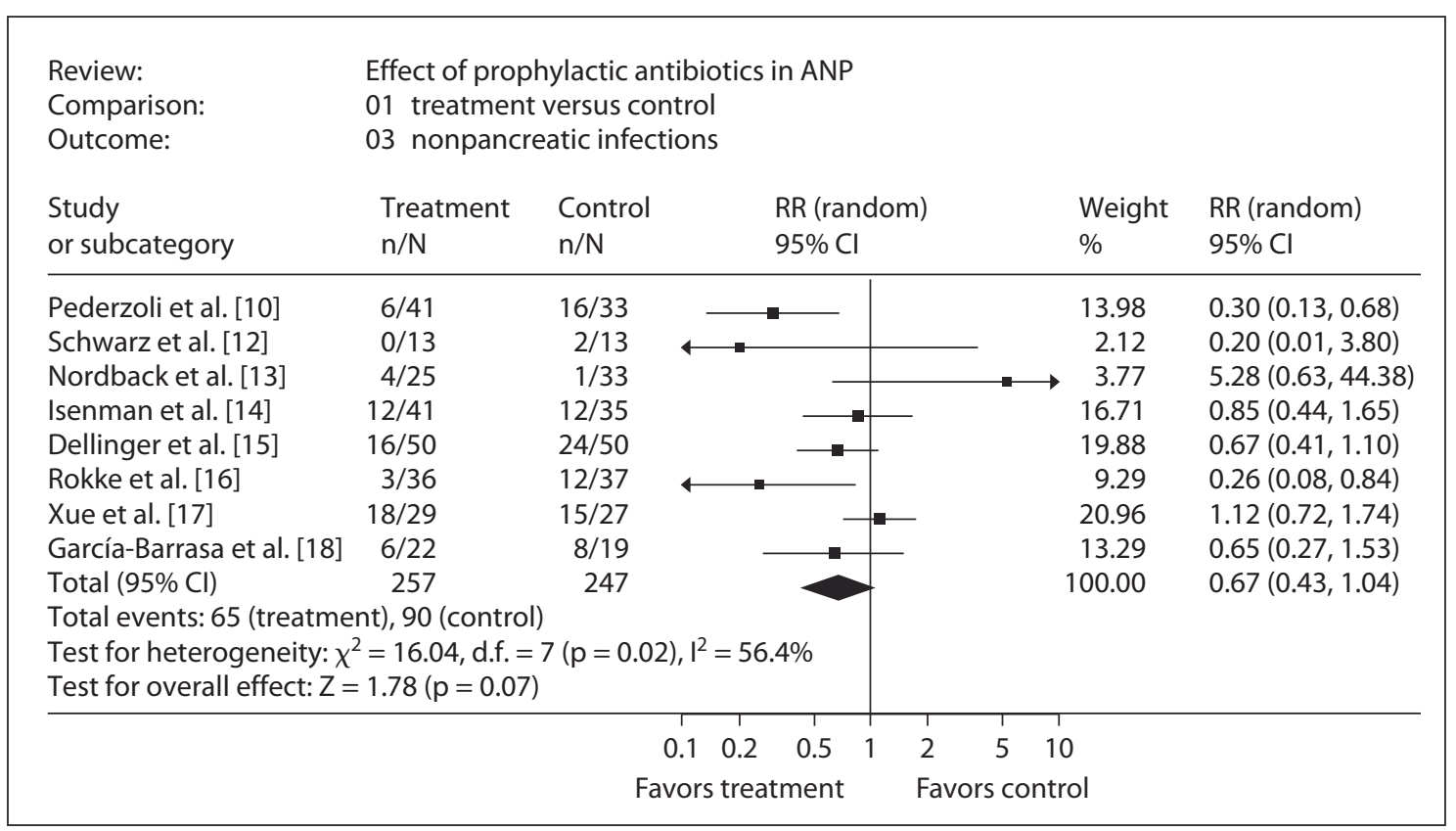

Fig. 4. Antibiotic prophylactic effect on NPN. 


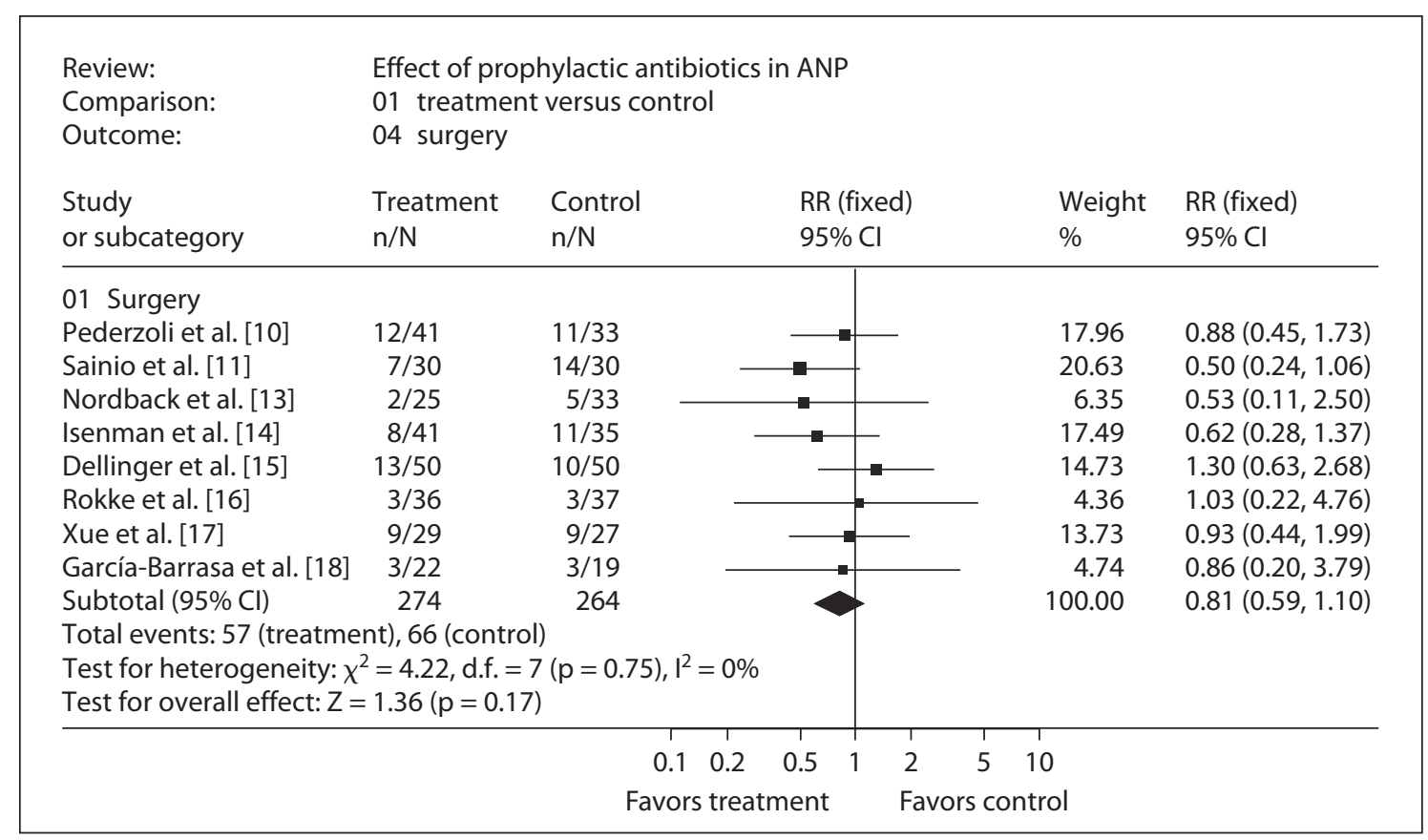

Fig. 5. Antibiotic prophylactic effect on surgery intervention.

0.07). The use of the other two types of antibiotic agents did not alter NPN rates (cephalosporins: RR 0.20, 95\% CI $0.01-3.80, \mathrm{p}=0.28$, and quinolone-based agents: RR 0.77 , $95 \%$ CI $0.46-1.30, \mathrm{p}=0.33$ ).

\section{Surgical Interventions}

As shown in figure 5, antibiotic treatment was not associated with a significantly reduced need for surgical interventions (RR $0.81,95 \%$ CI $0.59-1.10, \mathrm{p}=0.17$ ). When subgroup analyses were performed (table 2), no significant effects were found in single-center RCTs (RR 0.67, 95\% CI 0.42-1.08, p = 0.10), multi-center RCTs (RR 0.92, $95 \%$ CI $0.62-1.38, \mathrm{p}=0.4$ ) single-blinded trials (RR 0.74, $95 \%$ CI $0.50-1.10, \mathrm{p}=0.13)$, or double-blinded trials (RR $0.92,95 \%$ CI $0.56-1.51, \mathrm{p}=0.75)$. Furthermore, the type of antibiotic agent did not have an effect ( $\beta$-lactam: RR $0.97,95 \%$ CI $0.66-1.43, \mathrm{p}=0.14$; quinolone-based agents: RR $0.67,95 \%$ CI $0.34-1.35, \mathrm{p}=0.26$, and cephalosporins: RR 0.50, 95\% CI 0.24, 1.06, $\mathrm{p}=0.07$ ).

\section{Discussion}

In this study, data from RCTs in patients with ANP were evaluated to determine the efficacy of prophylactic antibiotic treatment. The outcomes of IPN, mortality,
NPN, and need for surgical intervention were analyzed. Data from nine randomized clinical trials were included. As summarized in table 2, trials included single-blinded and double-blinded, single-center and multi-center studies and different antibiotics were used. When data from all trials were combined, the reduction in IPN was significant when patients were treated prophylactically with antibiotics. Data were also evaluated in subgroups based on trial type and antibiotic used. We found no statistical difference in any of the four major outcomes when data from double-blinded RCTs were evaluated. IPN was significantly decreased in the antibiotic prophylaxis group compared to patients who did not receive antibiotic treatment in single-center trials, whereas NPN was reduced in the treatment group in the multi-center research. In single-blinded trials, only need for surgical intervention was reduced with antibiotic treatment. $\beta$-Lactam antibiotics reduced IPN and NPN rates, and the mortality rate was reduced in the cephalosporins treatment group; quinolone treatment had no effect on any outcome.

Data regarding efficacy of prophylactic antibiotic treatment in ANP are conflicting. Pederzoli et al. [10] found that antibiotic treatment prevented pancreatic sepsis, but the statistical analyses of these data have been questioned. Sainio et al. [11] showed a significant reduction of mortality when prophylactic antibiotics were 
used; however, the primary (one-side testing) and secondary (two-side testing) outcomes did not use the same Fisher exact test. No significant difference in mortality or IPN was found in Schwarz et al.'s trial [12]. The need for surgery was significantly reduced in a trial evaluating the early administration of imipenem, but in this trial only 7 patients were proven microbiologically to have IPN [13]. The first placebo-controlled, double-blinded trial to show that prophylactic antibiotics did not significantly reduce the risk of developing IPN was criticized [14], as only $70-80 \%$ of patients in the trial had CECT-proven pancreatic necrosis and there was a high crossover to an open antibiotic treatment. The second double-blinded, placebo-controlled trial [15], similar to Isenmann et al.'s trial [14], suggested that antibiotic prophylaxis was not efficacious [15]. In a 2007 trial, extrapancreatic infections, rather than mortality and pancreatic infection, were more frequent in the control group than the treatment group [16]. No significant differences between treatment groups were observed in another recent double-blinded and placebo-controlled trial, but only $41 \mathrm{pa}-$ tients were enrolled [17]. Another trial proved that antibiotic prophylaxis was not beneficial and that broadspectrum antibiotic treatment adversely increased the incidence of fungal infection [18].

Previous meta-analyses have yielded conflicting results. Villatoro et al. [19] concluded that antibiotic prophylaxis may prevent death from acute pancreatitis, but did not include the largest double-blinded trial [14]. The Sharma and Howden meta-analysis included only three trials [20]. The analysis by Golub et al. [21] found benefit in the use of prophylactic antibiotics, but the antibiotic evaluated doses penetrated effectively into the pancreas. A meta-analysis of five trials found no effect [22]. Another study found that prophylactic antibiotic treatment was associated with a significant reduction of pancreatic

feeding, so the effect of nutrition could not be evaluated in this study. We suggest that enteral nutrition should be used in future RCTs that evaluate prophylactic antibiotic use in ANP patients.

Contrary to much of the clinical research, studies in animal models of necrotizing pancreatitis show that prophylactic administration of antibiotics reduces mortality [38]. One reason for this may be the effect of nutrition. Another is that in clinical use, antibiotics may not be used early enough in the disease course. The correct diagnosis of AMP is based on clinical, CECT and laboratory examination making rapid diagnosis difficult. Due to this, the RCTs included in our analysis often could not reach the initially calculated sample size. Gallstones and alcohol were the main etiology of NAP. Also, patients in RCTs had very different rates of etiology. As with nutrition, because detailed descriptions of etiology were not found in RCT reports, we could not perform a subgroup analysis.

The utility of antibiotics in treatment of ANP may be masked by many factors. This meta-analysis suggests that prophylactic antibiotics reduce IPN but not mortality, NPN, or the need for surgical intervention in patients with ANP. We used fixed-effects or random-effects models to pool data from nine clinical trials according to heterogeneity. We also incorporated an updated meta-analysis on prophylactic antibiotics versus placebo in AMP, which, in addition to the trials included in a previous meta-analysis [24], included the two most recent RCTs [17, 18]. According to the available RCTs, prophylactic antibiotic plus enteral nutrition should be used in ANP therapy. To reveal the real effect of antibiotic prophylaxis, additional high-quality clinical trials must be performed. infection, NPN, and length of hospital stay, but did not prevent death or the need for surgical intervention [23]. A random-effects model was used in a recent meta-analysis suggesting that prophylactic antibiotics did not reduce IPN and mortality [24].

It is generally accepted that the gut barrier plays a very important role in the prevention of local and systemic infections. This means that nutrition, as well as the antibiotic, can impact patient outcome. When enteral and parenteral nutrition in patients with severe acute pancreatitis were compared, enteral nutrition was associated with an obvious reduction in infectious complications, but not with a significant change in mortality [31-37]. Unfortunately, few reports of RCTs state the method of

References
1 Working Party of the British Society of Gastroenterology; Association of Surgeons of Great Britain and Ireland; Pancreatic Society of Great Britain and Ireland; Association of Upper GI Surgeons of Great Britain and Ireland: UK guidelines for the management of acute pancreatitis. Gut 2005;54(suppl 3):iiiliiig.

2 Heinrich S, Schafer M, Rousson V, et al: Evidence-based treatment of acute pancreatitis: a look at established paradigms. Ann Surg 2006;243:154-168.

-3 Sainio V, Kemppainen E, Puolakkainen P, et al: Early antibiotic treatment in acute necrotising pancreatitis. Lancet 1995;346:663667.

-4 Baron TH, Morgan DE: Acute necrotizing pancreatitis. N Engl J Med 1999;340:14121417. 
5 Howes R, Zuidema GD, Cameron JL: Evaluation of prophylactic antibiotics in acute pancreatitis. J Surg Res 1975;18:197-200.

6 Finch WT, Sawyers JL, Schenker S: A prospective study to determine the efficacy of antibiotics in acute pancreatitis. Ann Surg 1976;183:667-671.

7 Craig RM, Dordal E, Myles L: The use of ampicillin in acute pancreatitis. Ann Intern Med 1975;83:831-832.

$\checkmark 8$ Beger HG, Bittner R, Block S, et al: Bacterial contamination of pancreatic necrosis. A prospective clinical study. Gastroenterology 1986;91:433-438.

$\checkmark 9$ Büchler M, Malfertheiner P, Friess H, et al: Human pancreatic tissue concentration of bactericidal antibiotics. Gastroenterology 1992;103:1902-1908.

$\checkmark 10$ Pederzoli P, Bassi C, Vesentini S, et al: A randomized multicenter clinical trial of antibiotic prophylaxis of septic complications in acute necrotizing pancreatitis with imipenem. Surg Gynecol Obstet 1993;176:480-483

-11 Sainio V, Kemppainen E, Puolakkainen P, et al: Early antibiotic treatment in acute necrotising pancreatitis. Lancet 1995;346:663667.

-12 Schwarz M, Isenmann R, Meyer H, et al: Antibiotic use in necrotizing pancreatitis: results of a controlled study. Dtsch Med Wochenschr 1997;122:356-361.

13 Nordback I, Sand J, Saaristo R, et al: Early treatment with antibiotics reduces the need for surgery in acute necrotizing pancreatitis - a single-center randomized study. J Gastrointest Surg 2001;5:113-118.

14 Isenmann R, Runzi M, Kron M, et al: Prophylactic antibiotic treatment in patients with predicted severe acute pancreatitis: a placebo-controlled, double-blind trial. Gastroenterology 2004;126:997-1004.

15 Dellinger EP, Tellado JM, Soto NE, et al: Early antibiotic treatment for severe acute necrotizing pancreatitis: a randomized, doubleblind, placebo-controlled study. Ann Surg 2007;245:674-683.

$\checkmark 16$ Rokke O, Harbitz TB, Liljedal J, et al: Early treatment of severe pancreatitis with imipenem: a prospective randomized clinical trial. Scand. J Gastroenterol 2007;42:771-776.
17 Xue P, Deng LH, Zhang ZD, Yang XN, Wan $\mathrm{MH}$, Song B, Xia Q: Effect of antibiotic prophylaxis on acute necrotizing pancreatitis: results of a randomized controlled trial. J Gastroenterol Hepatol 2009;24:736-742.

18 García-Barrasa, Borobia FG, Pallares R, Jorba R, Poves I, Busquets J, Fabregat J: A double-blind, placebo-controlled trial of ciprofloxacin prophylaxis in patients with acute necrotizing pancreatitis. J Gastrointest Surg 2009;13:768-774.

19 Villatoro E, Bassi C, Larvin M: Antibiotic therapy for prophylaxis against infection of pancreatic necrosis in acute pancreatitis. Cochrane Database Syst Rev 2006;4:CD002941.

20 Sharma VK, Howden CW: Prophylactic antibiotic administration reduces sepsis and mortality in acute necrotizing pancreatitis: a meta-analysis. Pancreas 2001;22:28-31.

21 Golub R, Siddiqi F, Pohl D: Role of antibiotics in acute pancreatitis: a meta-analysis. J Gastrointest Surg 1998;2:496-503.

22 Mazaki T, Ishii Y, Takayama T: Meta-analysis of prophylactic antibiotic use in acute necrotizing pancreatitis. Br J Surg 2006;93: 674-684.

$23 \mathrm{Xu}$ T, Cai QP: Prophylactic antibiotic treatment in acute necrotizing pancreatitis: Results from a meta-analysis. Scand J Gastroenterol 2008;43:1249-1258.

24 Bai Y, Gao J, Zou DW, Li ZS: Prophylactic antibiotics cannot reduce infected pancreatic necrosis and mortality in acute necrotizing pancreatitis: evidence from a meta-analysis of randomized controlled trials. Am J Gastroenterol 2008;103:104-110.

25 Toouli J, Brooke-Smith M, Bassi C, CarrLocke D, Telford J, Freeny P, et al: Guidelines for the management of acute pancreatitis. J Gastroenterol Hepatol 2002;17(suppl 1):1539.

26 Uhl W, Warshaw A, Imrie C, Bassie C, McKay CJ, Lankisch PG, et al: IAP guidelines for the surgical management of acute pancreatitis. Pancreatology 2002;2:565-573.

27 Nathens AB, Curtis JR, Beale RJ, et al: Management of the critically ill patient with severe acute pancreatitis. Crit Care Med 2004 32:2524-2536

28 Takeda K, Takada T, Kawarada Y, et al: JPN guidelines for the management of acute pancreatitis: medical management of acute pancreatitis. J Hepatobiliary Pancreat Surg 2006; 13:42-47.
29 John C, Theodore N, Pappas T: Necrotizing pancreatitis: diagnosis and management. Surg Clin N Am 2007;87:1431-1436.

30 Jadad AR, Moore RA, Carroll D, et al: Assessing the quality of reports of randomized clinical trials: is blinding necessary? Control Clin Trials 1996;17:1-12.

31 Marik PE, Zaloga GP: Meta-analysis of parenteral nutrition versus enteral nutrition in patients with acute pancreatitis. BMJ 2004; 328:1407.

32 Abou-Assi S, Craig K, O’Keefe SJ: Hypocaloric jejunal feeding is better than total parenteral nutrition in acute pancreatitis: results of a randomized comparative study. Am J Gastroenterol 2002;97:2255-2262.

33 Olah A, Pardavi G, Belagyi T, Nagy A, Issekutz A, Mohamed GE: Early nasojejunal feeding in acute pancreatitis is associated with a lower complication rate. Nutrition 2002;18:259-262.

-34 McClave SA, Greene LM, Snider HL, Makk LJ, Cheadle WG, Owens NA, Dukes LG, Goldsmith LJ: Comparison of the safety of early enteral vs. parenteral nutrition in mild acute pancreatitis. JPEN J Parenter Enteral Nutr 1997;21:14-20.

-35 Kalfarentzos F, Kehagias J, Mead N, Kokkinis K, Gogos CA: Enteral nutrition is superior to parenteral nutrition in severe acute pancreatitis: results of a randomized prospective trial. Br J Surg 1997;84:1665-1669.

-36 Gupta R, Patel K, Calder PC, Yaqoob P, Primrose JN, Johnson CD: A randomised clinical trial to assess the effect of total enteral and total parenteral nutritional support on metabolic, inflammatory and oxidative markers in patients with predicted severe acute pancreatitis (APACHE II $>$ or $=6$ ). Pancreatology 2003;3:406-413.

-37 Cao Y, Xu Y, Lu T, Gao F, Mo Z: Meta-analysis of enteral nutrition versus total parenteral nutrition in patients with severe acute pancreatitis. Ann Nutr Metab 2008;53:268275.

38 Fritz S, Hartwig W, Lehmann R, WillSchweiger K, Kommerell M, Hackert T, Schneider L, Büchler M, Werner J: Prophylactic antibiotic treatment is superior to therapy on-demand in experimental necrotizing pancreatitis. Crit Care 2008;2:R141. 